\title{
IMANÊNCIA E LATÊNCIA DOS PEQUENOS SONHOS DIURNOS, SEGUNDO ERNST BLOCH ${ }^{1}$
}

Rosalvo Schütz ${ }^{2}$

\begin{abstract}
Resumo $^{3}$
Para Ernst Bloch os pequenos sonhos diurnos são uma espécie de forma elementar de esperança, imanentes à vida humana e presentes em todas as suas fases. Estão sempre latentes e, mesmo que desprezados e ignorados, não deixam de emergir incessantemente da base material e social da nossa existência. Suas expressões, contudo, podem variar muito e, inclusive, podem ser instrumentalizadas ideologicamente para fins reacionários. Daí a importância de que sejam levados a sério numa perspectiva crítico-emancipatória, a fim de que seus potenciais subversivos não sejam desperdiçados. Sem levar em conta o significado crítico desses aportes de esperança primeira, qualquer projeto emancipatório seria irremediavelmente unilateral. Identificar, compreender e potencializar esses conteúdos de esperança é uma das tarefas mais desafiadoras e instigantes no horizonte da utopia concreta: pensamento comprometido com o novum, que se prefigura no front.
\end{abstract}

Palavras-chave: sonhos diurnos; esperança; Bloch.

\section{IMMANENCE AND LATENCY OF LITTLE DAYDREAMS BY ERNST BLOCH}

\begin{abstract}
For Ernst Bloch, the little daydreams are a kind of elementary form of hope, immanent to human life and present in all its phases. They are always latent and, even though they are despised and ignored, they never cease to emerge from the material and social basis of our existence. Their expressions, however, can vary widely and may even be ideologically instrumentalized for reactionary purposes. Hence the importance of being taken seriously in a critical-emancipatory perspective, so that their subversive potentials are not wasted. Not taking into account the critical significance of these contributions of first hope, any emancipatory project would be hopelessly one-sided. Identifying, understanding and enhancing these contents of hope is one of the most challenging and thoughtprovoking tasks on the horizon of concrete utopia: thinking committed to the novum, which is prefigured on the front.
\end{abstract}

Keywords: daytime dreams; hope; Bloch

\section{Ponto de partida}

A apresentação de um texto não deveria ser mais difícil do que o texto mesmo: senão seria melhor ler o original. Mas ele também não deve pretender substituir o texto, pois então aquele não precisaria mais ser lido. Além disso, como sabemos desde Jacques Rancière

1 Tradução própria do texto publicado originalmente em língua alemã em Zimmermann, Rainer (Org.). Ernst Bloch: Das Prinzip Hoffnung. Coleção: Klassiker Auslegen [Interpretar os Clássicos], organizada por Otfried Höffe, n. 56. De Gruyter: Berlin/Boston, 2018, p. 35-49. Título original: Immanenz und Latenz der kleinen Tagträume. DOI: 10.1515/9783110366136-006. N.T.

2 Docente de Filosofia na Universidade Estadual do Oeste do Paraná - UNIOESTE. Bolsista de produtividade do CNPq. A tradução é um dos resultados do pós-doutorado realizado na Universidade Católica do Rio Grande do Sul (PUCRS) entre 2019 e 2020.

3 Resumo e palavras-chave elaboradas apenas para a versão do texto em português. N.T. 
(2004), por detrás das ditas explicações ${ }^{4}$ de textos, muitas vezes se esconde uma versão própria do texto a qual pretende apresentar-se como a interpretação mais autêntica e verdadeira. Para que uma então uma explicação interpretativa ainda pode servir? Se é que ainda pode servir para algo, então enquanto uma humilde introdução e uma junção de indicações de aspectos, motivos ou mesmo pressupostos do texto. Assim, no melhor dos casos, ela pode motivar para a leitura própria do texto.

No caso deste artigo existe ainda outra especificidade, uma dificuldade especial: o texto a ser interpretado está escrito originalmente em outra língua! O que um autor latinoamericano, brasileiro, haveria de escrever sobre Ernst Bloch? Talvez possa, partindo da própria posição e ponto de vista, buscar compreender, por exemplo, por que Bloch está sendo lido cada vez mais no Brasil e, assim, contribuir para evidenciar a atualidade de seu pensamento. Pois é certo que Bloch está sendo lido cada vez mais entre nós, e sua teoria está indubitavelmente sendo recebida e trabalhada de modo estimulante, inovador e produtivo.

Já nos anos 70 do século passado, a filosofia e a teologia da libertação latinoamericanas haviam sido fortemente influenciadas por Bloch (cf. Hahn, 2007). Mesmo que indiretamente, ainda hoje essa influência pode ser claramente percebida em diversas áreas da sociedade, mas, especialmente, nos movimentos sociais. Além disso, obras de Bloch estão sendo traduzidas, textos escritos sobre ele, e até mesmo nas mídias vez por outra se ouve alguém recorrer a Bloch. De onde advém essa força de atração que a teoria de Bloch exerce sobre nós que nos encontramos aqui ao sul e do outro lado do Atlântico? Procurarei responder a essa pergunta recorrendo especialmente à seção sobre os "pequenos sonhos diurnos" do Princípio Esperança $(\mathrm{PE})$.

Que uma crítica autêntica dificilmente seja possível sem uma correspondente esperança de uma vida melhor é algo que já o pensador brasileiro Paulo Freire afirmou de diversos modos. Em sintonia com algumas formulações da Teologia da Libertação, para ele, denúncia e anúncio devem andar sempre juntos, pois somente assim, enquanto futuro aberto, se pode, segundo sua concepção, possibilitar o “inédito viável” (Freire, 2002, p. 94). Fundamentalmente, a esperança se enraíza - e daí também a possibilidade da crítica - na “vocação ontológica para o ser mais" (Freire, 2002, p. 72) dos humanos, pois apenas alguém

\footnotetext{
4 Lembrando que o presente texto foi escrito originalmente em alemão para dar conta especificamente da Parte I do Princípio Esperança: que trata dos Pequenos sonhos diurnos, publicado numa obra conjunta, com participação de autores de diversas nacionalidades, abordando todas as partes dessa obra, no contexto da coleção. N.T.
}

\begin{tabular}{|c|c|c|c|c|}
\hline Qevista Dialectus & Ano 10 & n. 21 & Janeiro - Abril 2021 & p. $208-225$ \\
\hline
\end{tabular}


que se mostra insatisfeito com o que está aí se põe a caminho no buscar de um ser diferente. Os seres humanos são inconclusos e, além disso, conscientes desse seu inacabamento. Desde Erich Fromm, Freire (2002, p. 45) pôde entender que todas as organizações e relações humanas que se voltam contra essa tendência do "ser mais" no ser humano tendem a se traduzir em uma práxis necrófila, servindo, majoritariamente, para a legitimação de opressões e de relações de dominação estabelecidas. Em contraposição a isso, a "vocação ontológica para o ser mais" não se coaduna com tal procedimento de uma práxis necrófila estando, antes, orientada pela esperança e pela superação das relações de opressão estabelecidas.

Já aqui os pensamentos de Freire e Bloch parecem se encontrar - e talvez seja por isso que a linha de pensamento desenvolvida por Bloch, por vezes, nos pareça tão familiar -, pois é justamente nesse contexto que Bloch inicia e valoriza a tematização dos pequenos sonhos diurnos: para ele, são essencialmente constitutivos da condição humana e nunca se deixam domesticar totalmente. O significado desse pensamento não é de ser subestimado, ainda mais na atualidade, pois, apesar da atual sensação de desesperança, crescente indiferença e para além de todo o sentimento de impotência diante do mundo 'lá fora', talvez seja possível constatar que os sonhos diurnos a todo instante perpassam a vida humana e têm, por isso, uma função alentadora e vivificante. A aparente desesperança sem saída da sociedade moderna, cuja lógica muitas vezes nos é ideologicamente apresentada como sendo a sociedade per se, é, para Bloch, apenas a expressão da "situação sem saída do ser burguês" (2005, p. 15), a qual não dever ser confundida com a vida humana enquanto tal. Sobre isso podemos ler em Bloch:

\begin{abstract}
A ideologia, sendo as idéias dominantes de uma época, é, de acordo com a frase definitiva de Marx, as idéias da classe dominante. Porém, como também a classe dominante é alienada de si mesma, sua ideologia reflete não só o interesse em apresentar o seu próprio bem-estar como sendo o bem-estar de toda a humanidade, mas também aquela imagem da nostalgia ou da superação num mundo livre da alienação - imagem que sobretudo na burguesia se chama cultura e mostrou a função utópica atuando em parte também naquela classe, que fora isso se sentia bem na sua alienação (2005, p. 149).
\end{abstract}

Bloch constata que, desde o nascimento até a idade mais avançada, essa ideologia é contradita na medida em que os pequenos sonhos diurnos estão constantemente presentes indicando os limites dessa sociedade: "Enquanto o homem se encontrar em maus lençóis, a sua experiência tanto privada quanto pública será perpassada por sonhos diurnos, por sonhos de uma vida melhor que a que lhe coube até aquele momento" (2005, p. 15). Eles são, por assim dizer, o ponto de partida de todas as utopias, constituem o fundamento a partir do qual o pensar 
e o agir rumo a um futuro aberto se tornam possíveis. Trata-se, portanto, da identificação de um importante pressuposto: tanto para Bloch quanto para Freire o ser humano é um ser aberto, estando ele mesmo inserido em um processo em devir e, sobremaneira, é só assim que a esperança é possível: "Somente ao se abandonar o conceito fechado e imóvel do ser surge a real dimensão da esperança" (Bloch, 2005, p. 28). Também para Freire não pode existir esperança quando alguém acredita que o mundo de qualquer forma já está totalmente determinado. Para ele a consciência de que o mundo, mesmo sendo sempre condicionado, não é determinado é um pressuposto dos mais importantes a fim de que seja possível avançar contra o sentimento de impotência política. Não existe, portanto, um mundo pronto e acabado e, por isso, também não pode haver uma teoria definitiva a qual eventualmente pudesse nos transmitir uma verdade última. Na medida em que o próprio ser humano é parte constitutiva do devir processual do mundo, também ele não pode ser tomado como um ser acabado e pronto, ou, como expressa Freire: ele é um ser inconcluso. A isso, no entanto, é bom que se acrescente também que o ser humano pode estar consciente de que ele mesmo está em condição de compreender a história a partir de sua capacidade transformadora, na medida em que ele próprio efetiva mudanças inovadoras.

Bloch é um materialista (cf. Lorenzoni, 2015), ou seja, ele parte das tendências e latências daquilo que se nos apresenta sem impor ideais externos à realidade. Isso, no entanto, de modo algum significa que ele sacrifica as dimensões subjetivas dos seres humanos diante daquilo que se nos apresenta: também essas dimensões pertencem ao seu conceito de natureza (cf. Bicca, 2013). Natureza não é sinônimo de matéria morta. Espírito e natureza deveriam ser concebidos como pertencentes a uma unidade originária. Portanto, Bloch não define ideais a partir dos quais a realidade pudesse ser medida ou mesmo adequada. Não procura algo fora do mundo a fim de modificar a sua orientação. E talvez seja por isso que inicia seu Princípio Esperança, de modo semelhante ao que Marx inicia $O$ Capital, tematizando suas estruturas elementares. Metodologicamente, portanto, em Bloch os pequenos sonhos diurnos ocupam, de certa forma, o lugar das mercadorias no Capital de Marx: a forma elementar presente e pressuposta em toda a obra. Como afirma Marx: "A riqueza das sociedades em que domina o modo de produção capitalista aparece como uma 'imensa coleção de mercadorias', e a mercadoria individual como sua forma elementar. Nossa investigação começa, portanto, com a análise da mercadoria” (1983, p. 45). Em vez de iniciar, como Marx, pela tematização das 
mercadorias, Bloch inicia com a tematização das formas elementares de esperança: os pequenos sonhos diurnos.

É a partir dos sonhos diurnos que se possibilita a reconstrução, ampliação e análise das utopias. Em Freire é afirmado algo semelhante na medida em que indica que processos autênticos de libertação só podem partir dos próprios oprimidos, tomando como base seus próprios sonhos, assim como suas próprias contradições: caso contrário, os mesmos continuariam sendo tratados como simples objetos ou massa anônima a ser manipulada. Assim, pode-se dizer que em Bloch os pequenos sonhos diurnos estão sempre pressupostos embora ele não permaneça fixado neles. Estabelecendo mais um paralelo com Freire, pode-se dizer que a libertação precisa, mesmo que partindo das esperanças mais cotidianas, da crítica e da práxis concreta a fim de conseguir colocar em questão as condições de opressão contra as quais algo precisa ser empreendido. Essa direção teórica básica também Bloch indica claramente no Princípio Esperança: “O presente livro não trata de outra coisa que não o esperar" ${ }^{5}$ (Hoffen) para além do dia que está aí. [...] E o caminho leva dos pequenos sonhos acordados para os robustos" (2005, p. 21). Nossos sonhos diurnos são, portanto, a primeira indicação material de que o próprio futuro se aninha diretamente no presente, e mais, de que o mesmo não precisa ser 'trazido de fora' para dentro do nosso mundo.

Talvez pudéssemos aqui chamar à palavra um pensamento de dois pensadores brasileiros, Hugo Assmann e Jung Mo Sung (2000), os quais afirmam que, sem pequenas "vivências de esperança”, os engajamentos políticos e sociais mais amplos não são possíveis, pois aqui se trataria de uma experiência a ser pressuposta e que está em diálogo com um algo fundamental: embora pequenos desejos e esperanças de uma vida melhor perpassem toda a existência humana, eles, no entanto, precisam de oportunidades para poderem se realizar, para poderem se expressar em vivências e experiências sensíveis para, assim, poderem ser, inclusive, compreendidos como tais. Por experiências desse tipo, segundo os autores, cada um poderia se convencer de que a tendência imanente para os sonhos não é uma ilusão vazia, mas que ela pode ter consequências concretas. Nessa medida eles têm, antes, uma importante função pedagógica, pois, por seu meio, pode se tornar consciente, para cada um que agir de modo ativo e solidário no mundo, que todos os aparentes becos sem saída são, na verdade, consequência de um olhar deficitário sobre o mundo, uma vez que este sempre pode ser modificado.

\footnotetext{
Considerando que o termo 'esperar' tem um caráter passivo, que em alemão corresponde a Warten, consideramos que a palavra 'esperançar' corresponderia de modo mais adequado à palavra Hoffen, utilizada no original, que advém de Hoffnung/esperança.
}

\begin{tabular}{|c|c|c|c|c|}
\hline Qevista Dialectus & Ano 10 & n. 21 & Janeiro - Abril 2021 & p. $208-225$ \\
\hline
\end{tabular}


Isso certamente está em sintonia com Bloch quando afirma, por exemplo, que a impotência diante de estruturas sociais de injustiça que, muitas vezes, nos é sorrateiramente sugerida, não passa da expressão de uma "situação sem saída do ser burguês [que] é estendida à situação humana, a todo o ser" (2005, p. 15). Os pequenos sonhos diurnos, no entanto, já estão sempre nos rastros de um caminho no qual nos contrapomos a esse aparente beco sem saída. Assmanann/Mo Sung e Bloch, portanto, coincidem na convicção de que nossa vida é perpassada por pequenos sonhos diurnos e de que, além disso, é possível aprender algo dos mesmos que pode nos conduzir ao sonho de um mundo melhor e a uma práxis equivalente. $\mathrm{O}$ mais importante nessa reflexão talvez seja a convicção de que nenhum ser humano tende para a acomodação e que o esperançar não é um produto pronto ou uma ideia introduzida desde o exterior, pois já está latente desde sempre e a todo momento em cada ser humano. Entretanto, parece que também pode acontecer, caso não se viabilizem alternativas práticas e históricas adequadas, que essa condição fundamental seja agenciada por fatores externos e condenada ao fracasso ou instrumentalizada de forma reacionária.

\section{Sonhos diurnos enquanto constitutivos do humano}

$\mathrm{Na}$ medida em que os sonhos diurnos estão desde logo enraizados no mundo, eles não podem ser constituídos ou mesmo reduzidos a uma perspectiva puramente iluminista, pois nesta a natureza geralmente é considerada como algo que precisa ser dominado por uma racionalidade superior a ela. Sonhos despertos estão numa esfera, por assim dizer, pré-racional, provêm do obscuro do "instante vivido". Por isso, para Bloch, o caráter utópico do ser humano, embora possa ser alcançado e tematizado pelo pensamento crítico, tem sua origem na própria natureza, ainda que, eventualmente, esta seja especificamente a natureza humana. Pode-se, inclusive, afirmar que a utopia já está 'naturalmente' disponível na vida humana, que ela é, inclusive, constitutiva de própria vida humana. Prova disso é que não podemos nos decidir arbitrariamente por um desejo, por um querer: "Sim, espera-se pelo próprio desejo, até que ele se torne mais claro" (Bloch, 2005, p. 29).

Entretanto, como o ser humano não está deterministicamente condicionado pela natureza, estando também condicionado social e historicamente, os sonhos e desejos humanos também surgem direcionados e incluídos nesses contextos. Mas, mesmo sendo humanamente constitutivos, os desejos, sonhos e utopias humanas nem sempre estão imunes em relação a ideologias conservadoras: mesmo os pequenos sonhos diurnos podem ser instrumentalizados. 
Eles, portanto, não são necessariamente críticos: “A vida de todos os seres humanos é perpassada de sonhos diurnos, que em parte são apenas uma fuga insossa e até enervante, e até presa para enganadores. Outra parte, porém, instiga, não permite se conformar com o precário que aí está, não permite a resignação” (Bloch, 2005, p. 14). A isso ainda se soma que eles podem ser apropriados e trabalhados de modos diferenciados individualmente, como afirma o próprio Bloch: "O desejo sensacionalista é trivial e ilusório para almas delicadas (Weichgeschaffenen) e triviais, profundo para as fortes, capazes de enxergar" (2005, p. 48). Mesmo assim, ninguém consegue se dizer satisfeito enquanto permanecer alguma falta ou necessidade que não tenha sido satisfeita de modo apropriado. "A vontade que se trata provém da penúria e não desaparecerá enquanto esta não for eliminada” (2005, p. 48). Assim, Bloch recorre à natureza humana mesma, a um impulso por transformação antropologicamente fundamentado, de modo que o aspirar a um mundo melhor esteja sempre presente, aspirar este que nunca pode ser ideologicamente paralisado por completo. "A ânsia pelo melhor permanece, por mais que o melhor seja impedido. Se o que se deseja vier a ocorrer, de qualquer maneira será surpreendente" (2005, p. 48).

Bloch enfatiza que, na filosofia, a tematização da esperança e do futuro como sendo algo constitutivo em meio ao presente não foi muito valorizada, permanecendo antes em contraposição à tradição filosófica hegemônica. Por isso, a perspectiva indicada tem como consequência, assim como por pressuposto, um conceito diferenciado de filosofia, que deve ser considerado se tendo em vista que o ser humano é compreendido como aquele que está desafiado a se lançar "ativamente naquilo que vai se tornando [Werdende]" (2005, p. 13); portanto, alguém que não se satisfaz com o pensamento apenas daquilo que passou. Ele não se dá por satisfeito com o pressuposto "de que todo saber seria meramente rememoração. [...] Rememoração de idéias [...], de coisas passadas” (Bloch, 2005, p.19) indicando, assim, para um conceito de filosofia (cf. Bicca, 1976, p. 22-24) que pode antes ser compreendido "como o início de uma teoria que não se resigna a contemplar e explicar" (Bloch, 2005, p.19). Essa perspectiva perpassa toda a obra blochiana, desde os Spuren (Bloch, 1977a), de 1930, até o Experimentum mundi (Bloch, 1977b) de 1975.

Para Bloch, o pensar exige transposição. Uma transposição que, por um lado, não simplesmente fantasia com o Novum a partir de pensamentos vazios ou desde perspectivas idealisticamente fixadas, mas que também, por outro lado, não se orienta só pelo que está instituído, por aquilo que se apresenta como se não fosse passível de mudança. O Novum 
justamente só é alcançado a partir do interior desse campo tenso entre aquilo que está constituído e do ainda-não constituído. Porém, o ainda-não se encontra, na forma de utopia concreta, inserido naquilo que está constituído. De modo que pode ser dito que um pensar enquanto transposição compreende "o novo como algo mediado pelo existente em movimento" (2005, p. 14). Além disso, para poder ser receptivo a esse novo, o pensar necessita uma transposição de si mesmo, pois só por esse meio o novo pode ser levado a sério: o pensamento precisa se deixar surpreender e influenciar pelo devir do mundo mesmo para, desse forma, na medida em que deixa conscientemente o novo surgir, alcançar uma esperança compreendida: "Docta spes, a 'esperança compreendida', torna claro assim o conceito de um princípio que não mais deixa o mundo" (Bloch, 2005, p.17).

$\mathrm{O}$ aqui e agora, tanto da sociedade quando da natureza, é, portanto, o ponto de partida. Nele já está contido o futuro como potência imanente. Utopia concreta, concebida enquanto esperança compreendida, só pode partir desse ponto: "Seu espaço é a possibilidade real e objetiva dentro do processo, na via do próprio objeto" (Bloch, 2005, p. 17). Em vez de ser deduzida desde algo impossível ou de uma terra de ninguém apenas imaginada, a utopia é conquistada justamente a partir da proximidade: "Da mesma forma o aqui e agora, que estão sempre se iniciando na proximidade, constituem uma categoria utópica, sim, a mais central de todas" (2005, p. 22). Mesmo que já esteja sempre aí, ela, no entanto, nem sempre é evidentemente consciente ou mesmo compreendida, e é por isso que "necessitamos de um telescópio mais potente, o da consciência utópica afiada, para atravessar justamente a proximidade mais imediata" (2005, p. 23), para compreender aquilo que já está latente, aquilo que pulsa nos mais simples sonhos diurnos e, assim, poder compreendê-los e até mesmo potenciá-los. O esforço subjetivo, o esforço do conceito, portanto, não pode ser substituído. Aliás, ele mesmo já pertence à compreensão materialista do mundo de Bloch: "ajudante da parteira" do Novum, de quem o mundo, de qualquer forma, já está prenhe.

O fato, portanto, de Bloch iniciar o primeiro capítulo do Princípio Esperança com os pequenos sonhos diurnos tem um peculiar significado pedagógico: com isso ele aponta para uma postura que, ao invés de simplesmente desprezar a vida cotidiana, lhe atribui, ao contrário, um papel fundante. "Principia-se, portanto, com os sonhos diurnos do tipo mediano, escolhidos leve e livremente desde a juventude até a velhice" (Bloch, 2005, p. 21). A fase da vida à qual se refere, no nosso entender, tem aqui, para nossa reflexão, importância secundária. Mais 
importante é que, com isso, ele pôde provar a relevância utópico-revolucionária dos sonhos diurnos, possibilitando, assim, também a evidência empírica da própria utopia concreta.

\section{Sonhos diurnos enquanto potência críticas}

Se, por um lado, a esperança quer ser apreendida e compreendida, por outro lado, ela impulsiona para adiante cada ser humano desde seu nascimento: "Desde cedo na busca. Completamente ávido, gritando. Não se tem o que se quer" (Bloch, 2005, p. 29). Desde o seu nascimento, no ser humano vive o frescor, "o outro, com o qual se sonha" (2005, p. 29). Uma das primeiras formas de expressão do caráter utópico permanentemente presente no ser humano, que pode ser percebido já no comportamento na idade infantil, se manifesta, sobretudo, na brincadeira: "Brincar é transformar-se, ainda que na certeza de voltar a ser o que era antes. $\mathrm{O}$ brincar transforma a seu gosto a própria criança, os seus amigos, todas as coisas à sua volta em algo estranhamente familiar" (2005, p. 30).

Não se deveria desprezar esse desejar que se manifesta já no brincar: "Ao olhar uma pedra colorida, germina muito do que ele desejará pra si mais tarde” (Bloch, 2005, p. 30). Mesmo quando a criança se torna 'invisível' ou procura um esconderijo onde ela possa imaginar um mundo peculiar, já está em ação a utopia: "Nisso se delineia diante dos olhos o próprio quarto, a vida livre que virá" (2005, p. 30). No fundo, as brincadeiras aventurosas das crianças já podem ser tomadas até mesmo como ensaios de libertação: “Assim, aos sete ou oito anos, o espaço estreito torna-se amplo, as coisas mais estranhas acontecem nele (quando a escada é retirada do chão e puxada para cima" (2005, p. 31). Na maioria das vezes, aí se 'alcança' uma terra estranha, uma terra dos desejos, a qual também "não desaparece nem depois disso" (2005, p. 31).

Bloch também aventa que podem surgir sonhos diferenciados entre crianças e jovens proletários e burgueses, o que significaria que mesmo os desejos infantis já são condicionados pelos contextos sociais. Em todo caso, nesses primeiros desejos está contido algo que, de qualquer modo, já sempre está “indo nitidamente além do que está dado" (2005, p. 33). Num ou noutro caso, "a vontade despedaça a casa, onde tudo é enfadonho e o melhor é proibido" (2005, p. 33). Também impulsos eróticos, assim como a amizade, são aventados e seu conteúdo utópico abordado: "aquilo que une e promove a amizade é apenas a expectativa comum de um futuro comum" (2005, p.34). 
Bloch observa que, mesmo que nessa fase da vida muitas vezes se trate de "esperanças sem paciência", "sonhos idealistas, de uma imaturidade peculiar" (Bloch, 2005, p. 36) esses desejos indicam sempre e fundamentalmente para estruturas gerais de esperança. Evidentemente que também esses primeiros sonhos não estão isentos da possibilidade de serem degradados a uma exploração desumanizadora. Como afirma Bloch, "a luz no fim do túnel frequentemente espreitada no céu burguês tornou-se, todavia, uma mancha de sangue. Para os tolos e atordoados, o homem forte chamava-se Hitler" (2005, p. 36). Portanto já aqui, na tematização dos sonhos de infância e juventude, Bloch deixa claro que a esperança também pode ser instrumentalizada.

Com a idade, os sonhos se modificam, embora não diminuam: “Aquilo que é importante continua sempre faltando. Portanto, o sonho não pára de se infiltrar nas lacunas" (Bloch, 2005, p. 37). Do mesmo modo, a qualidade dos sonhos vai se diferenciando: "Contudo, como se pode ver, os sonhos particulares do tipo mais maduro não deixam de ser às vezes tolos, às vezes exóticos" (2005, p. 39). E é justamente aí que Bloch reconhece diferenças significativas de classe: "Daí o homem médio, o pequeno-burguês proletarizado, mas sem consciência proletária, sonhar muito mais com castelos na lua do que o cidadão de posses, que sabe o que tem" (2005, p. 40). Como nem sempre está claro o porquê de seus sonhos não se realizarem, pode daí surgir uma espécie de raiva ressentida que acaba modificando os desejos em "desejos de vingança”. Segundo Bloch, no entanto, esses desejos raivosos são minoritários, pois "há também os afetuosos, inofensivamente tolos e coloridos" (2005, p. 33).

Aqui também é criticado o mundo pequeno-burguês, especialmente quando percebemos que os pequenos sonhos diurnos dos "cidadãos possuidores" são deveras limitados. Ademais, segundo Bloch, eles se constituem muito mais a partir do tédio do que da necessidade. Trata-se desse "estrato de modo algum homogêneo, mas progressivamente homogeneizado, [que] satisfaz-se em ter as necessidades que lhe são despertadas pela vitrine para ele modelada" (2005, p. 40). Assim, “os desejos burgueses, ao menos os da vida privada, acabam fazendo com que eles queiram cortar também o seu pedaço do bolo, sem transformar a padaria" (2005, p. 41). Em contraposição a isso, podemos, segundo Bloch, reconhecer claramente os sonhos não burgueses pelo que estes indicam para "uma vida sem exploração" (Idem) e também porque

a felicidade não decorre da infelicidade do outro nem se mede por ela. Isso porque a pessoa ao lado não é mais a barreira para a própria liberdade, mas o lugar em que ela se concretiza. Em lugar da liberdade para comprar [...] a imaginada vitória na luta de classes proletária (Bloch, 2005, p. 42). 
Mesmo na velhice, quando os desejos parecem recuar, suas imagens, no entanto, permanecem. Nos sonhos diurnos dos mais idosos, podemos perceber, do mesmo modo que em outras idades, a procura por uma vida não alienada. Bloch pleiteia uma concepção de velhice diferente daquela marcada pela compreensão de que nessa idade parece restar apenas o sofrimento. Dá preferência a uma imagem de velhice que se deixa definir enquanto o alcance de uma "época de colheita": "a velhice mesma não tem culpa pela feiura da imagem que produz" (Bloch, 2005, p. 41). Afinal, na sociedade alienada parece ser assim mesmo: "O vinho e o bolso continuam sendo o desejo permanente na idade trivial, e nem sempre apenas trivial. Vinho, mulher e canções: esta associação se desfaz e a garrafa detém preferência" (2005, p. 43).

No entanto, a velhice em si não é culpada disso. Mas, de fato, "é estranha a facilidade com que nos deixamos interromper pelo novo, pelo inesperado" (Bloch, 2005, p. 47), e a sociedade tardo-burguesa enfatizou isso a tal ponto que até mesmo chega a fetichizar esse aspecto: "De modo bem resumido, pode-se dizer, portanto: o simples sofrimento na velhice [...] é constituído sobre [...] uma sociedade burguesa tardia que desesperadamente põe uma maquiagem de juventude" (2005, p. 45).

Esse olhar dominante da sociedade atual sobre a velhice, porém, pode, segundo Bloch, ser posto em questão quando, por exemplo, lançamos um olhar sobre outras sociedades: "E sociedades que não receavam encarar o fim, diferentemente da burguesia - que hoje está em declínio - tinham e viam a velhice como um desabrochar desejável e bem-vindo" (2005, p. 45). Que a esperança, existente na sociedade instituída, reserve tão pouco lugar para as pessoas com mais idade pode significar que a velhice não cabe adequadamente na lógica estabelecida. Portanto, as esperanças que surgem com mais força nessa fase da vida podem conter algo especialmente progressivo, justamente por não serem reconhecidas pela lógica da sociedade atual, até mesmo chegando a ser temidas por ela:

[...] e não se pode mais afirmar que a velhice, apesar de sua sobriedade, seria pura e simplesmente reacionária, e a juventude, apesar de seu viço, pura e simplesmente progressista. [...] Assim, justamente o amor à tranquilidade pode estar mais distante da agitação capitalista do que uma juventude que confunde agitação com vida (Bloch, 2005, p. 47).

Daquilo que foi dito até aqui podemos afirmar que em todos os pequenos sonhos diurnos, e isso em todas as fases da vida, já sempre estão contidas potências críticas. Elas, 
entretanto, podem ser neutralizadas e até mesmo instrumentalizadas (Vieira, 2010, p. 41). Por isso, numa perspectiva revolucionária, eles deveriam ser consciente e explicitamente (docta spes) apoiados, aprofundados e apreendidos. A seguir buscaremos demonstrar, por meio de mais alguns casos exemplares, o significado dos pequenos sonhos diurnos para o conjunto da obra Princípio Esperança.

\section{Exemplo de imagens de desejos na saúde, nos esportes e na medicina}

Se Bloch inicia seu Princípio Esperança com os pequenos sonhos diurnos e os torna uma espécie de "formas elementares' de sua teoria, então de algum modo eles devem ser perceptíveis no conjunto de sua obra. De fato, na descrição e investigação da esperança eles sempre de novo aparecem como pontos de partida concretos, o que claramente aponta para a sua posição materialista: o objeto tem primazia e não pode ser substituído por ideais estranhos a ele. Segundo Enrique Dussel, Bloch parte sempre dos conteúdos e materiais e os relaciona com um "possível novo futuro". Assim, quando, por exemplo, se refere aos impulsos, afetos etc., segundo Dussel, Bloch estaria se referindo ao que poderia ser chamado de 'ser-vivente' que o ser humano compartilha com os demais seres-viventes: sua condição material mais elementar. Com isso os conteúdos positivos dos próprios impulsos vitais de esperança poderiam nos levar à superação do existente, podendo, portanto, subsidiar um possível interesse revolucionário (Dussel, 2011, p. 454-455) desde algo que se origina no nosso próprio impulso vital.

Assim, por exemplo, acontece explicitamente no último capítulo do primeiro volume e no primeiro capítulo do segundo volume do Princípio Esperança, onde são abordadas as utopias nos esportes, saúde e medicina. Vejamos. Mesmo que de um ponto de vista ideológico o conjunto da sociedade instituída ou mesmo a vida pessoal de cada um nos seja apresentada como sendo a melhor possível, segundo Bloch, não nos acostumamos com as carências: "A carência daquilo que sonhamos não dói menos, ao contrário" (Bloch, 2006, p. 09). O ponto de partida da utopia e, por isso, da crítica à realidade estabelecida, encontra justamente nesse "não dói menos" impulsos decisivos. "De modo que a vontade não apenas tenta viver além de suas próprias condições, mas além das circunstâncias precárias” (2006, p. 9-10). Mediante exemplos, como o esporte, a saúde e a medicina, Bloch procura evidenciar que, apesar da sua tendencial redução a formas e objetivos instrumentalizados, sempre surge algo com perspectivas críticas e manifestando um desejo de transposição. 
No caso do esporte, facilmente poderíamos ceder à tentação de aceitar que aí se trata antes de simples treinos corporais, de modo que não consigamos extrair dele algum potencial utópico ou implicações políticas. Bloch, no entanto, se contrapõe decididamente a tal posição: "Exercício físico sem treinar o cérebro significa, em última análise, ser bucha de canhão e, antes, violento (Schläger). Não existe esporte apolítico” (Bloch, 2006, p. 11). E aponta, assim, para um conteúdo utópico do esporte: "Mesmo o exercício atlético continua desejante, esperançoso. [...] Visa também fazer mais, poder ser mais com o corpo do que lhe foi cantarolado no berço" (2006, p. 11). O esporte, portanto, é considerado como algo mais do que uma simples atividade que tem por objetivo o desempenho do corpo e a disputa: "Constitui um desejo esportivo ter um controle do corpo tal que, ainda na rampa de saltos, quando a pessoa está voando, cada situação seja familiar, mesmo a novidade, o exagero" (2006, p. 11). Tendo em vista essa perspectiva blochiana, certamente seria possível lançar uma nova luz sobre o esporte, pela qual provavelmente poderia se tornar possível libertá-lo de muitos limites, aos quais ainda hoje está submetido.

Até mesmo o ser humano doente sonha de modo especial com uma vida diferente, mesmo que seu sonho se oriente mais pela libertação de algo do que por algo novo: "o enfermo não tem a sensação de que lhe falta algo, mas de que tem algo a mais. [...] Pelo fato de o enfermo não saltitar nem pular, fazem-no tanto mais seus desejos" (Bloch, 2006, p. 13). Esse tipo de sonho já sempre esteve presente na história humana, o que pode ser percebido em diversos vestígios: "Existe a pomada que de súbito cura os malefícios, existe o poço do qual os velhos emergem jovens outra vez, um meio privilegiado para tornar constante o bem fugaz que é a beleza feminina" (2006, p. 13). Provavelmente a esperança por saúde seja uma das mais elementares a nos mobilizar na vida cotidiana: "Visões idealizantes contra a doença devem ter sido, ao lado das contra a fome, as mais antigas, e desde já a cura era considerada batalha vencida. Em contrapartida, o corpo debilitado também persegue os mais belos sonhos de uma vida melhor" (2006, p. 15).

Dos sonhos relacionados com o esporte e a saúde, Bloch chega àqueles sonhos que - do modo mais amplo possível - interligam a humanidade com a medicina. Segundo Bloch, com isso objetivamos especialmente o desejo não apenas de não sermos expostos a doenças, mas também de tornar o nosso corpo menos vulnerável:

Em razão disso, o médico não é imaginado aqui como um sapateiro que, bem ou mal, conserta novamente o antigo. Pelo contrário, é desejado como renovador, capaz de 
libertar a carne não apenas de sua fraqueza adquirida, mas mesmo da inata. Porque também o organismo saudável pode obter muito mais auxílio (Bloch, 2006, p. 16).

Tendencialmente, no entanto, a medicina não produziu utopias destacadamente fortes. E isso se deve sobremaneira à sua função restaurativa: "Os anseios dos próprios doentes não se estendem a esse ponto. Importa-lhes que seja afastado o sofrimento, é o que basta" (Bloch, 2006, p. 20). Ou seja, quando estamos doentes o que queremos é nos libertar da doença. Assim, o médico geralmente se satisfaz bem concretamente "em rechaçar o desfecho da doença: a morte. Luta contra a debilidade adquirida na carne, não contra a inata” (2006, p. 21). Além disso, essa limitação também estaria relacionada com "a origem da ciência médica europeia no estoicismo (Stor). Essa escola confiava no curso natural das coisas, não queria rompê-lo em ponto algum, adequando-se ao estoicismo em tudo" (2006, p. 21).

Já desde o tempo de Hipócrates, o ‘bom médico’ apoia os efeitos da natureza. Mesmo que isso tenha possibilitado 'abstratos melhoramentos' e "possibilitado a conexão com o objetivamente possível", por esse meio a medicina muito facilmente foi simplesmente colocada a serviço da classe dominante: "Isso ocorre, sobretudo, em consideração a um produto útil para a classe dominante, na era do pequeno ser humano na linha de montagem" (Bloch, 2006, p. 17). Em vez de melhorar a vida humana, como, por exemplo, pela redução dos impulsos agressivos mediante a criação orgânica, tais possibilidades, segundo Bloch, são antes bloqueadas por tal concepção de medicina. Tal perspectiva orgânica de criação/educação, aplicada apenas a seres humanos individuais, Bloch, no entanto, percebe como algo problemático e, com isso, indica para implicações mais amplas da saúde: "Porém, a própria sociedade que reproduz precisa ser primeiramente procriada, para que o novo teor nutritivo humano não seja determinado pelas demandas dos antropófagos” (2006, p. 18).

Interessante que aqui Bloch chega a uma concepção crítica da sociedade justamente desde formas elementares de esperança; no caso, desde nossos 'sonhos orgânicos': a busca da saúde. Assim se explicita cada vez mais o caráter social do conceito de saúde, de modo que também simultaneamente se tornem evidentes perspectivas ideológicas ocultas:

A saúde não é absolutamente apenas uma noção médica, mas predominantemente um conceito social. Restabelecer a saúde significa, na verdade, levar o doente àquela espécie de saúde reconhecida na respectiva sociedade, sim, que na realidade foi primeiramente formada na própria sociedade (2006, p. 23). 
Assim se torna observável que cada sociedade constitui suas próprias referências a partir das quais recém se torna claro o que pode ser nominado saudável ou não:

\footnotetext{
Na sociedade capitalista, a saúde é a capacidade de trabalhar; entre os gregos, era a capacidade de desfrutar; na Idade Média, era a capacidade de crer: a enfermidade era vista como pecado [...]. Desse modo, não existe em lugar algum uma saúde predefinida e constante (Bloch, 2006, p. 23).
}

Portanto, os sonhos e desejos da medicina podem, assim como todos os outros, ser instrumentalizados. Com isso, entretanto, o potencial crítico dos sonhos diurnos não é inviabilizado. Para, no entanto, poder evidenciar a crítica aí imanente, necessitamos de um esforço teórico o qual tendencialmente conduz a uma práxis social consciente. No exemplo aqui aventado, se torna possível visualizar o que as utopias médicas têm em comum com as utopias sociais, na medida em que estes sonhos objetivam uma "corporeidade" que, segundo Bloch, "só proporcionaria prazer, não dor, e cuja velhice não teria por destino a labilidade. Portanto, é essa luta contra o destino que, apesar de tudo, alia as utopias médicas e sociais" (Bloch, 2006, p. 24).

Assim, pouco a pouco se torna claro que a saúde só pode ser melhorada significativamente quando, simultaneamente, também a sociedade vai sendo correspondentemente transformada: “[...] os seres humanos não terão andar ereto enquanto a própria vida social continuar tortuosa" (Bloch, 2006, p. 28). Isso significa que não é mediante procedimentos estritamente medicinais sobre supostas inevitáveis determinações da natureza que se pode interferir na sociedade. Segundo Bloch, essa era a linha defendida por Malthus, segundo o qual "a razão da miséria reside na contradição 'natural' entre irrestrito empenho humano por propagação e o aumento limitado de víveres" (2006, p. 25) como se a miséria humana pudesse ser entendida "supondo que as forças produtivas crescem lentamente, a crise somente se manifesta como crise de carestia, não como crise de abundância" (2006, p. 25).

Para Bloch, por outro lado, e por isso mesmo, a procura por uma saúde autêntica está permanentemente interligada com a luta por uma sociedade mais saudável. Assim, por fim, podemos até mesmo chegar à conclusão de que a própria sociedade é "suja e doente" e, portanto, precisa de uma "atenção clínica e planejamento". Para além disso, ao que tudo indica, faz-se necessário desenvolver um novo conceito de saúde: "Que é uma saúde que meramente torna as pessoas maduras para serem novamente expropriadas, desgastadas, baleadas? [...] $\mathrm{O}$ capitalismo é insalubre - mesmo para os capitalistas" (2006, p. 27). Tudo isso, no entanto, não 
impede que a influência significativa da vida sobre uma sociedade tornada saudável continue sendo uma das esperanças mais visíveis e constantes, "pois a saúde visa a ser desfrutada, e não consumida" (2006, p. 28).

\section{Observações finais}

Do acima tematizado, somos levados a concluir que o esperançar emerge da nossa simples existência humana natural, para não dizer ontológica, na medida em que se erige a partir dos pequenos sonhos diurnos. Essa dimensão foi especialmente destacada pelo filósofo argentino Miguel Vedda (2008, p. 85-86): os pequenos sonhos diurnos seriam uma espécie de antídoto crítico para a exagerada razão instrumental do nosso atual "mundo administrado".

Diante disso, surge a questão de como deveria ser entendida a afirmação de Bloch de que "o que importa é aprender a esperar (Hoffen)" (2005, p. 13). Não é a esperança algo que está imanente em nossa vida desde o início? E aqui chegamos a um ponto muito importante: os sonhos diurnos já estão sempre presentes, no entanto, como vimos, eles podem ser neutralizados e instrumentalizados. E é assim - e por isso - que o Princípio Esperança envereda por um caminho que tem por objetivo uma práxis explicitamente transformadora e pressupõe que todo ser humano seja compreendido enquanto um ser socialmente constituído e perpassado por utopias.

É nesse sentido que, portanto, a esperança autêntica precisa sempre ser aprendida. Para tanto, o processo de aprendizagem aqui intencionado deveria estar constantemente em diálogo com os pequenos sonhos diurnos, pois, por fim, trata-se de uma procura quase detetivesca (Vidal, 2013), com uma metodologia filosófico-crítica. Com Paulo Freire se poderia, nesse contexto, dizer que a libertação dos oprimidos só pode acontecer em conjunto 'com eles' e, de forma alguma, pode acontecer como algo vindo de fora 'para eles'. Afinal, o esperançar, na sua forma mais efetiva, só se torna possível lá onde os seres humanos estejam em condições de se apropriar conscientemente daqueles sonhos que emergem desde as situações mais concretas e cotidianas de suas vidas. É a partir desses sonhos que se torna possível o “inédito viável”, aquele ainda-não-ser, mas que é concretamente possível.

Com o olhar voltado para a esperança compreendida, a docta spes, é que recém se torna possível desvendar a práxis social a partir de onde os autênticos potenciais revolucionários dos pequenos sonhos diurnos podem ser desdobrados. Nesse processo eles podem ser libertos de suas fantasias ilusórias, abstratas e ideológicas e a força revolucionária de seus conteúdos 
subversivos pode ser liberada. Se, por um lado, a perspectiva blochiana não se deixa aprisionar em uma perspectiva determinista, por outro, ela também não pode ser reduzida a uma simples fantasia abstrata, para a qual tudo é possível. Dentre outras coisas, certamente, podemos estar de acordo com Bloch quando afirma que, com essa postura, se abrem novas perspectivas de compreensão, transposição e ação, incluindo aí um novo acesso ao marxismo: "Isso proporciona, também em termos pedagógicos e de conteúdo, um novo acesso a um marxismo criativo, a partir de novas premissas dos tipos subjetivos e objetivos" (2005, p. 27). Logo, não por acaso essa formulação blochiana está exercendo uma força de atração considerável em perspectivas libertárias não "norte-eurocêntricas” (Dussel, 2011), inclusive no Brasil.

\section{Referências}

ALBORNOZ, Suzana. Ética e Utopia: ensaio sobre Ernst Bloch. Porto Alegre: Movimento, 2006.

ASSMANN, Hugo; MO SUNG, Jung. Competência e sensibilidade solidária: educar para a esperança. Petrópolis: Vozes, 2000.

BICCA, Luiz. Libertação da Natureza? In: Síntese - Revista de Filosofia, abril 2013. Belo Horizonte, 2013.

BICCA, Luiz. Marxismo e Liberdade. São Paulo: Edições Loyola, 1987,

BLOCH, Ernst. Experimentum Mundi. Frage, Kategorien der Herausbringens, Práxis. Enrst Bloch Gesamtausgabe in 16 Bände/Band 15. Frankfurt am Main: Suhrkamp, 1977b.

BLOCH, Ernst. O Princípio Esperança, V. I. Tradução de Nélio Schneider. Rio de Janeiro: EdUERJ: Contraponto, 2005.

BLOCH, Ernst. O Princípio Esperança, V. II. Tradução de Werner Fuchs. Rio de Janeiro: EdUERJ: Contraponto, 2006.

BLOCH, Ernst. Prinzip Hoffnung. Erst Bloch Gesamtausgabe in 16 Bände/Band 05. Suhrkamp: Frankfurt am Main, 1977.

BLOCH, Ernst. Spuren. Erst Bloch Gesamtausgabe in 16 Bände/Band 01. Suhrkamp: Frankfurt am Main, 1977a.

DUSSEL, Enrique. Ética de la Liberación en la Edad de la Globalización y de la Exclusión. Madrid: Trotta, 2011.

FREIRE, Paulo. Pedagogia da esperança: um reencontro com a Pedagogia do Oprimido. Notas: Ana Maria Araújo Freire. Rio de Janeiro: Paz e Terra, 1992.

\begin{tabular}{|l|l|l|l|l|}
\hline Qenista Dialectus & Ano 10 & n. 21 & Janeiro - Abril 2021 & p. 208 - 225 \\
\hline
\end{tabular}


FREIRE, Paulo. Pedagogia do oprimido. Rio de Janeiro: Paz e Terra, 2002.

HAHN, Paulo. Blochs Dimension der Natur- und Sozialutopie und ihr Einfluss im lateinamerikanischen Denken sowie die Konzepte Ungleichzeitigkeit und Multiversum als Grundbedingungen für das Verständnis und als Perspektive für einen interkulturellen Dialog. Aachen: Wissenschaftsverlag Mainz, 2007.

LORENZONI, Anna. Materialismo e Utopia: Estudo sobre a interpretação blochiana das Onze Teses de Marx sobre Feuerbach. Dissertação. Toledo: Programa de Pós-Graduação em Filosofia/UNIOESTE, 2015.

MARX, Karl. Das Capital I. In: MEW, Bd. 23, Berlin, 1974.

RANCIÈRE, Jacques. O mestre ignorante - Cinco lições sobre a emancipação intelectual. Tradução de Lílian do Valle. 2 ed. Belo Horizonte: Autêntica, 2004.

VEDDA, Miguel. Calles sin recuerdo: fenomenología de la gran ciudad en Siegfried Kracauer y Walter Benjamin. In: Buchenhorst, Ralph; Vedda, Miguel: Observaciones urbanas: Walter Benjamin y las nuevas ciudades. Buenos Aires: Editorial Gorla, 2008.

VIDAL, Francesca. Sherlock Holmes nos estudos culturais: procura de vestígios com Ernst Bloch. (Sherlock Holmes in der Kulturwissenschaft - eine Spurensuche mit Ernst Bloch). Tradução de Rosalvo Schütz e Adriano Steffler. In: Revista Dialectus, ano 01, n. ${ }^{\circ}$ 02, janeirojunho, 2013.

VIEIRA, Antonio Rufino. Marxismo e Libertação: estudos sobre Ernst Bloch e Enrique Dussel. São Leopoldo: Nova Harmonia, 2010.

ZIMMERMANN, Rainer (Org.). Ernst Bloch: Das Prinzip Hoffnung. Coleção: Klassiker Auslegen, organizada por Otfried Höffe. De Gruyter: Berlin/Boston, 2018, p. 35-49. 